Check for updates

Center for Health and Migration, Vienna, Austria

Cite this as: $B M J 2022 ; 376: 0401$ http://dx.doi.org/10.1136/bmj.0401 Published: 16 February 2022

\section{The European Union needs a policy and strategy to secure access to healthcare for undocumented migrants}

\author{
Creating an evidence base to support policy and practice should be an urgent objective for the \\ research and policy making communities, argues Ursula Trummer
}

\section{Ursula Trummer Head of Center}

Undocumented migrants are among the most vulnerable migrant groups. For people who enter or stay in countries through irregular routes, and therefore lack the legal rights to live in or transit through a country, the associated health threats can be high and access to health services severely restricted.

Irregular migration receives almost constant attention in the popular press and a substantial focus in global and European discussions on health and migration. Despite this attention a clear policy on how to include undocumented migrants in public health systems while they reside in European territory has not been formulated with sufficient clarity.

Three of the four policy pillars in the European Agenda on Migration, which was launched in 2015, address irregular migration as needing to be prevented and combatted, as it threatens to "corrod[e] the system" of migration governance. The "New Pact on Migration and Asylum" launched in September 2020 confirms the aim of combatting irregular migration flows and to act against a business of smuggling. ${ }^{1}$ However, official reliable data on the number and movements of undocumented migrants are generally and globally not available. Crises like the covid-19 pandemic also fuel irregular movements and put additional pressure on those already living in a country undocumented.

The European Charta of Fundamental Rights defines the obligation of governments to safeguard human rights and access to health for everybody. However, neither the European Agenda on Migration nor the New Pact on Migration and Asylum specify how the human right to health should be implemented in practice. Furthermore, regulations on access to public health systems are defined by nation states, for the EU there are 27 different regulations.

A recent analysis of legal entitlements for access to healthcare for undocumented migrants in 26 countries (including $18 \mathrm{EU}$ member states) shows that the most common approach is to restrict legal access to emergency treatment. ${ }^{2}$ Although the argument is often made that opening healthcare to undocumented migrants is not affordable and jeopardises a country's health care system, single studies indicate that costs of exclusion may exceed costs of inclusion. 34 Nevertheless, solid evidence on economic costs is still urgently needed.

Policies of exclusion are often accompanied by strategies to open some limited access to healthcare for undocumented migrants. This leads to a health care infrastructure operating in parallel to the official public health system.

Studies from Europe have also described the strategies service providers have adopted to safeguard access to healthcare for undocumented migrants while countries stay restrictive towards irregular migration. Providers manage paradoxical demands through "functional ignorance" and "structural compensation." ${ }^{5}$ Functional ignorance means that service providers ignore the status of undocumented migrants, so they can provide healthcare and not involve immigration officials. In practice, the decision to provide or deny treatment to an undocumented migrant is often left to an individual health professional, which puts a heavy load on healthcare workers. Structural compensation means that non-governmental organisations become important stakeholders in service provision, setting up structures in parallel to compensate for the lack of appropriate and accessible services provided by the official public health structures.

Public health policy makers need to proactively resolve the question of how to integrate undocumented migrants into public health care regimes. There are at least three strong reasons to do so. Firstly, there is nothing more dangerous for a public health system than to ignore marginalised groups, especially when it comes to communicable diseases. Secondly, the Sustainable Development Goals of good health and wellbeing for all and reduction of inequalities cannot be met without integrating vulnerable groups. Lastly, it is not fair to leave the decision to treat or not to treat a person in need to healthcare professionals working on the frontline.

It is a humanitarian and public health responsibility to provide basic care for undocumented migrants. A prerequisite to meet this responsibility is a good evidence base on the drivers, stakeholders, conditions, and numbers of irregular migration.

So far, evidence is scarce and policies are disconnected from the findings of available studies. Creating a much needed evidence base, and developing policies and practices based on it, should be an urgent objective for the research and policy making communities.

Competing Interests: none

Provenance and peer review: not commissioned, not peer-reviewed

Acknowledgments: The author thanks the country experts collaborating on the analysis of legal entitlements for 2020; list of experts athttp://c-hm.com/wpcontent/uploads/2021/03/CHM-all-pages.pdf 


\section{OPINION}

1 European Commission. A fresh start on migration: Building confidence and striking a new balance between responsibility and solidarity, Press release 23 September 2020, Brussels.

https://ec.europa.eu/commission/presscorner/detail/en/ip_20_1706

2 Trummer U, Novak-Zezula S. NowHereland revisited in times of pandemic. Infographic, explanatory note and five landscapes. 2021. CHM, Vienna, http://c-hm.com/wp-content/uploads/2021/03/CHMall-pages.pdf

3 Gottlieb N, Trummer U, Davidovitch N, etal. Economic arguments in migrant health policymaking: proposing a research agenda. Global Health 2020;16:113.

doi: 10.1186/s12992-020-00642-8. pmid: 33218359

4 Trummer U, Krasnik A. Migrant health: the economic argument. EurJ Public Health2017;27:590-1. http://c-hm.com/wp-content/uploads/2019/10/migrant-health_the-economic-argument.pdf. doi: 10.1093/eurpub/ckx087 pmid: 28961880

5 Trummer U, Simonnot N, Vanbiervliet F. Access to Health Care for Undocumented Migrant Children. European Regulations and Practices. International Journal of Applied Ethics, Dilemata año 82016, No 21: 21-34, http://c-hm.com/wp-content/uploads/2019/09/DilemataUTNS-

FV_May2016.pd 